\title{
Heparan sulfate: a ubiquitous glycosaminoglycan with multiple roles in immunity
}

\section{David Anak Simon Davis and Christopher R. Parish*}

Cancer and Vascular Biology Group, Department of Immunology, The John Curtin School of Medical Research, Australian National University, Canberra, ACT, Australia

Edited by:

Deirdre Coombe, Curtin University, Australia

\section{Reviewed by:}

Fulvio D'Acquisto, Queen Mary

University of London, UK

Ralph D. Sanderson, University of

Alabama at Birmingham, USA

*Correspondence:

Christopher R. Parish, Cancer and Vascular Biology Group, Department of Immunology, The John Curtin School of Medical Research,

Australian National University,

Building 131, Garran Road, Canberra,

ACT 2601, Australia

e-mail: christopher.parish@anu.

edu.au
Heparan sulfate (HS) is a highly acidic linear polysaccharide with a very variable structure. It is ubiquitously expressed on cell surfaces and in the extracellular matrix and basement membrane of mammalian tissues. Synthesized attached to various core proteins to form HS-proteoglycans, HS is capable of interacting with various polypeptides and exerting diverse functions. In fact, a bioinformatics analysis of mammalian proteins that express a heparin/HS-binding motif and are associated with the immune system identified 235 candidate proteins, the majority having an intracellular location. This simple analysis suggests that HS may, in fact, interact with many more components of the immune system than previously realized. Numerous studies have also directly demonstrated that HS plays multiple prominent functional roles in the immune system that are briefly reviewed in this article. In particular, the molecule has been shown to regulate leukocyte development, leukocyte migration, immune activation, and inflammatory processes.

Keywords: glycosaminoglycan, heparan sulfate, heparanase, hematopoiesis, homing, inflammation

\section{INTRODUCTION}

Heparan sulfate (HS) is a glycosaminoglycan (GAG) that is ubiquitously expressed on cell surfaces and in the extracellular matrix (ECM) and basement membrane (BM). Each HS molecule is a linear polysaccharide composed of repeating disaccharides of hexuronic acid and D-glucosamine that can exhibit immense structural diversity due to substitution to varying extents with sulfate groups and epimerization of glucuronic acid to iduronic acid, with areas of high sulfation and glucuronic acid epimerization being co-located in "hot spots" throughout the molecule (Figure 1). HS is structurally related to heparin, an extremely highly sulfated form of HS that is restricted to mast cells. The biosynthesis and modification of HS chains is thought to take place within the endoplasmic reticulum, Golgi apparatus, and trans Golgi network, which in the end produce unique HS chains that are covalently attached to a range of core proteins to form HS-proteoglycans (HSPG) (Figure 1) $(1,2)$. After synthesis HS chains can be modified by the endoglycosidase, heparanase (3), and endosulfatases, Sulf1 and Sulf2 (4-6), to regulate HS availability and function. Although the core proteins can function independently of the HS chains they carry (7), HS predominantly dictates the ligand-binding capability and therefore the biological roles of HSPG (8). Furthermore, while different cell types may express similar core proteins, the HS chains these core proteins carry can be markedly distinctive, resulting in HSPG with highly diverse yet specialized roles in mammalian physiology $(8,9)$. In this mini-review, we will discuss some of the contributions of HS to the functioning of the immune system, notably leukocyte development, leukocyte migration, immune activation, and inflammatory processes.

\section{DIFFERENT CELLULAR LOCATIONS OF HS CHAINS}

In general, cell surface HSPGs includes members of the transmembrane syndecans (syndecan-1-4) and glycosylphosphatidylinositol (GPI)-linked glypicans (glypican 1-6). ECM/BM associated HSPGs are comprised of perlecan, collagen type XVIII and agrin. These HSPGs are collectively termed "full-time" HSPGs. "Part-time" HSPG include cell surface CD44 (isoform 3 is HSlinked) and extracellular betaglycan, testican, and neuropilin (8, 10). Secretory vesicle-associated serglycin is a HSPG that is exclusively expressed intracellularly, particularly in mast cells (11). Furthermore, HSPG can also be localized in the nucleus where they potentially regulate gene transcription (12-16).

\section{PREVALENCE OF HS-BINDING PROTEINS IN THE MAMMALIAN IMMUNE SYSTEM}

Due to the structural similarities between HS and heparin, the latter is often used as an experimental model for biochemical studies of HS-protein interactions and predicting potential HS-binding partners. Several heparin-binding proteins are known to carry the "consensus" heparin/HS-binding motifs XBBXBX or XBBBXXBX ( $B$ being the basic amino acids arginine, lysine, or histidine and $\mathrm{X}$ being one of a range of aliphatic/aromatic amino acids) (17). If correctly displayed in the secondary structure and optimally positioned within the three-dimensional conformation of polypeptides, these sequences are hypothetically capable of facilitating strong ionic interactions with negatively charged GAGs $(17,18)$. Based on this simple amino acid sequence criterion, we screened for protein sequences matching selected G0 terms in the Ensembl database (release 72) with a custom Python script for murine gene products that carry these motifs and are listed on the 
UniProt database (www.uniprot.org) as being reported to have immunological functions. We identified a total of $235 \mathrm{HS}$-binding proteins in the mouse genome (Table 1), a list that includes known

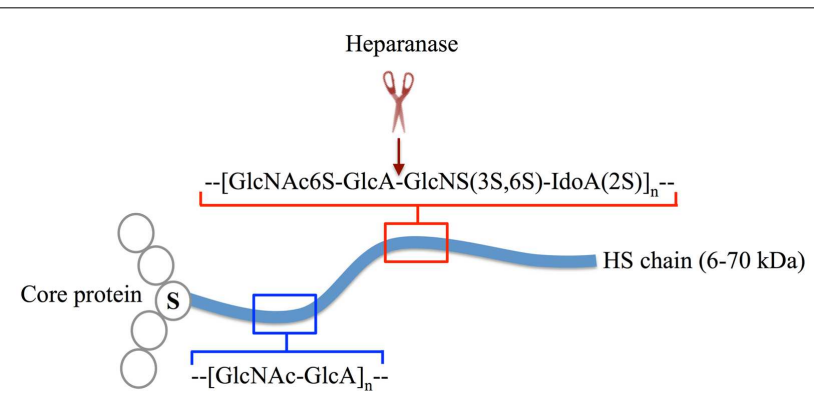

FIGURE 1 |The structure of HSPG. HS chains (blue line) are linear polysaccharides composed of repeating disaccharide subunits, which in their unmodified form are D-glucosamine and D-glucuronic acid (blue box). During synthesis, HS chains are covalently attached to core proteins (open circles) at serine (S) residues. A single HSPG molecule may carry multiple HS chains or contain other glycosaminoglycans other than HS (not shown). $\mathrm{HS}$ modifications include various degrees of $\mathrm{O}$ and $\mathrm{N}$-sulfation and epimerization of D-glucuronic acid to D-iduronic acid by HS-modifying enzymes (red box) (1). The modifications occur in regions (hot spots) along the polysaccharide chain, these hot spots being separated by regions of low sulfation. Post-synthesis structural alterations are primarily mediated by the endo- $\beta$-glucuronidase, heparanase, which cleaves HS chains within highly sulfated regions (cleavage site indicated by red scissors and arrow) (3).
HS-binding proteins and many potential new ligands for HS. An intriguing feature of this analysis was that $66 \%$ of the molecules that potentially bind HS are expressed intracellularly, with only $18 \%$ being exclusively expressed on the cell surface and only $10 \%$ being in the extracellular compartment. Remarkably, only one HS-binding protein, the HS degrading enzyme heparanase, was identified that can be expressed in intracellular and extracellular compartments as well as being able to associate with plasma membranes. This finding is consistent with the multiple functional roles of the enzyme.

Despite earlier reports claiming that HS negatively regulates gene transcription primarily by repressing the activity of p300 and pCAF histone acetyltransferase $(14,15)$, the bioinformatics screen implies that intracellular HS plays a more elaborate role in dictating cellular responses to various stimuli. Thus, it is predicted that HS interacts with several regulators of histonemodifying enzymes, such as Jarid2 (motif: MKRRHI), Kat6a (LHHLRM, KKVKK, RRVRK), and Mll1 (LRRFRA, IKKLRA, LKKAKA, VHRIRV, KKVKR, RHLKK) alongside key molecules that are involved in signal transduction and regulation of gene transcription, notably Vav1 (VKHIKI), STAT5A (KRIKR), STAT6 (KKIKR), Bcl6 (WKKYKF), Bcl11a (KHMKK), Ciita (LKRLKL), PTBP3 (VHRVKI, HRFKK), Lck (VKHYKI), IRAK1 (RRAKK), IRAK4 (HHIHR), Foxj1 (FKKRRL), Syk (RKAHH), ITK/TSK (IKHYHI), Card11 (KRFRK), Zap70 (KKLFLKR), Jak3 (IHKLKA, AKKLKF, RRIRR), and Cblb (RHFHH) and some components of the NF- $\kappa$ signaling pathway including NFKB2 (YHKMKI),

Table 1 | Hypothetical HS-interacting proteins.

\begin{tabular}{|c|c|c|}
\hline Cellular location & Total & Protein \\
\hline Extracellular & 24 & $\begin{array}{l}\text { Masp1, Ccl25, Osm, II9, Bmp4, Inhba, Pdgfb, Scg2, Hc, Fam20c, Wnt2b, Lrrc17, Gas6, C7, } \\
\text { ॥1a, Wnt5a, Cxcl12, Al182371, C4b, Cxcl5, C8b, Ccl17, Serping1, Ccl28 }\end{array}$ \\
\hline Intracellular, plasma membrane, and extracellular & 1 & Hpse \\
\hline Intracellular and plasma membrane & 3 & Blk, Flt1, Flt3 \\
\hline Intracellular and extracellular & 2 & $\operatorname{lsg} 15, \operatorname{Prg} 4$ \\
\hline Plasma membrane and extracellular & 8 & Tgfb1, Vegfa, Enpp3, Ctsg, C8a, Ptpro, Adam17, Enpp1 \\
\hline
\end{tabular}

List of murine proteins that carry "consensus" heparin/HS-binding motifs. The motifs adapted for bioinformatic screens are the standard motifs, which are primarily XBBBXXBX or XBBXBX (17) (http://gduserv.anu.edu.au/ cameron/protein. htm/). Short motifs are truncated versions of the standard motifs XBBBBX, BBXBB, or $B B X X X B B$ ( $B$ = basic amino acids $R, K, H ; X=A, V, I, L, M, F, Y, W$ ). Only proteins in the UniProt database (www. uniprot.org) that are known to play immunological roles are listed. 
IKBKG (MRKRHV), and Nkap (RRAKK, KKAKK, KKYKK). Interestingly, in the Rag1 protein, the presence of a HS-binding motif adjacent to a site critical for DNA binding (560D, UniProt) (AKRFRY), and overlapping the site that is essential for DNA hairpin formation [971F and 972R, UniProt (19)] (RRFRK), may imply a role for HS in regulating $\mathrm{V}(\mathrm{D}) \mathrm{J}$ recombination.

It is not surprising that cytokines including IL-1 $\alpha$ (LKKRRL), IL9 (HRVKR), TGF- $\beta 1$ (VKRKRI), and chemokines such as CCL17 (KHVKK), CCL19 (RRLKK), CCL25 (ARKRLVHM), CCL28 (VKRRRI), CXCL5 (KKAKR), and CXCL12 (VKHLKI) also carry HS-binding motifs, presumably allowing HS to act as their atypical receptors. Moreover, HS-binding motifs are also present on the cognate receptors for soluble factors such as the cytokine receptors IL-2R $\alpha$ (HRWRK) and IL7R (KKVKH) and the chemokine receptors CCR3 (WKFFHA), CCR7 (AHRHRA), and CXCR5 (YRRRRL), indicating new roles for HS in regulating leukocyte homeostasis and trafficking. In addition, HS may regulate the availability of crucial components in the immunological synapse as indicated by the presence of HS-binding motifs in the leader sequences of ICOSL (WKKLHV) and CTLA4 (LRRYKA). The presence of HS-binding motifs in CD22 (KKARR) and CD40L (KKLKR) also suggests additional roles for HS in cell-cell communication and $\mathrm{T}$ cell costimulation.

Examination of the innate immune system reveals that, although HS is already known to interact with TLR-4 (20), it appears that HS may also be recognized by other TLRs, including cell surface TLR-1, TLR-2, and TLR-6, and endosomal TLR-8 and TLR13. To be more precise, the HS-binding motifs appear to be in the extracellular domains of TLR-4 (RHIFWRR) and TLR-2 (IRRLHA) and in the cytoplasmic domains of TLR-1 (HRARH) and TLR-6 (YHKLRA and HRARH). For the endosomal TLRs, both motifs (LKKLHL and LKKKHF) are facing luminal for TLR-8, and cytoplasmic (HRLRK) and luminal (LKRLKI) for TLR13. It is possible that HS is involved in regulating downstream signaling when the motifs are present in the TLR cytoplasmic domains. In contrast, when these motifs are facing the luminal or extracellular space, HS may be a ligand or a regulatory component that modulates the interaction between a TLR and its cognate ligands. Furthermore, HS-binding motifs are also present on inflammasome components such as Nlrp3 (LKKFKM), Nlrc4 (LKKMRL, RHIHR), and Aim2 (LKRFKY), implicating a role for HS in regulating the activation of inflammatory caspases. In another aspect of innate immunity, several studies have reported that heparin and HS are able to interact with several components of the complements system, including $\mathrm{C} 1$ (21), C1q, C1 inhibitor, C2, C4, C4b, C4bp, C6, C8, C9, Factor B, Factor D, Factor H (22), MASP1, MASP-2 (23), and complement receptors CR3 (CD11b/CD18) (24) and CR4 (CD11c/CD18) (25). In support of these observations, we have identified the presence of HS-binding motifs in complement proteins such as C4b (FRKFHL), Hc/complement C5 (FHKYKV), C7 (KRLYLKR), C8a (WRKLRY), and C8b (KRYRH) as well as regulatory components of the complement machinery including MASP-1 (KHWRR), Serping1 (HKIRK), and CD93/complement component C1q receptor (YHKRRA), further highlighting the role of HS as a major modulator of the complement system (26).
However, it should be noted that more in-depth analyses are required to assess the validity of these predicted interactions, in particular the demonstration that the predicted HS-binding sites are correctly presented within the secondary structure and final three-dimensional conformation of the putative HS-binding proteins. Also, there are known HS-binding proteins that lack the heparin/HS-binding motifs used in this analysis, suggesting that the list of binding proteins identified in this screen may, in fact, be an under estimate. Thus, at face value, the data set implies that a wide range of HS-binding proteins participate in the immune system.

\section{FUNCTIONAL ROLES OF HS IN IMMUNITY}

Despite the previous section suggesting that there are many unknown HS-protein interactions that may control the immune system, there are a number of well-established functional roles for HS in immunity. Indeed HSPGs, through their HS chains, are involved in a broad spectrum of biological processes, profoundly influencing development (27), homeostasis (28), and the progression of many diseases (29). In the case of the immune system, HSPGs are fundamentally involved in regulating cell adhesion, cytokine and chemokine function, sensing tissue injury, and mediating inflammatory reactions. Each of these functional roles will be briefly discussed below, with specific examples given which highlight each function.

\section{REGULATOR OF CELL ADHESION}

Cell adhesion molecules are important to facilitate and regulate cell-cell signaling, migration and activation of leukocytes during development, homing, and recruitment to inflammatory sites. For example, of particular relevance to leukocytes development in the bone marrow is the receptor complex on hematopoietic stem cells (HSCs) comprised of CD45 and Mac-1 (CD11b/CD18) that has been shown to bind to surface HS on bone marrow-derived stromal cells and facilitate strong adhesion (30). In a related study, the HSPG glypican-3 enhances the antagonizing effect of tissue factor pathway-inhibitor (TFPI) on CD26, the stromal-bound ectopeptidase that is involved in cleaving surface CXCL12, a typical ligand for CXCR4 on HSC. As a result, glypican-3 indirectly supports the directional homing of grafted HSC toward, and their retention in, the bone marrow (31). Similarly, in the thymus a particular subset of cortical epithelial cells known as thymic nurse cells are reported to express high levels of highly sulfated HS that is thought to aid thymocyte adhesion and facilitate T cell development (32-35).

During an inflammatory response, HS positively regulates the recruitment of inflammatory cells at three different stages based on the following observations. First, endothelial surface HS can reduce neutrophil rolling velocity via L-selectin-mediated cell adhesion (36). Second, once attached, the HS-mediated Mac-1CD44v3 interaction enhances the binding of leukocytes to the endothelial surface to drive extravasation (37). Finally, within the endothelial ECM/BM, collagen type XVIII promotes leukocytes infiltration in again an L-selectin-dependent manner (38, 39). However, the role of HS in the adhesion of leukocytes to the endothelium can occur paradoxically, in a biphasic manner. Under physiological conditions, glycocalyx HSPGs of pulmonary endothelial cells are known to impede neutrophil adhesion (40). 
Following the induction of an experimental sepsis model of acute lung injury, the localized production of TNF- $\alpha$ activates endothelial cells to produce heparanase, which in turn catalyzes the partial degradation of HS constituents of the glycocalyx. The loss of HS results in a significant increase in neutrophils binding (40), presumably via neutrophils L-selectin binding to residual endothelial HS and via cytokine-induced endothelial P- and Eselectin (41). Additionally, reduction (in wild-type mice) or deletion (in knockout mice) of syndecan-1 from murine endothelial cells strongly accentuates antigen-specific lymphocytes infiltration into inflammatory sites during a delayed-type hypersensitivity reaction (42).

\section{MODULATOR OF CYTOKINE AND CHEMOKINE FUNCTION}

Soluble factors, such as cytokines and chemokines, are crucial to support growth, maintain homeostasis, and orchestrate immune cell trafficking across various locations. However, some of these molecules are inactive or susceptible to degradation in their native, soluble form. Furthermore, these factors need to be timely presented at the right site to exert their anticipated functions. HSPGs have been implicated in modulating various aspects of cytokine and chemokine function $(43,44)$.

HS-proteoglycans interact with various cytokines primarily on target cells or act as atypical cytokine receptors on cytokine presenting cell. The former situation enables HPSGs to regulate the availability and influence the interaction between cytokines and their cognate receptors on target cells. For example, the binding of cell surface HS to cytokines such as IL-7 and IFN- $\gamma$ proved critical to protect them against proteolysis $(45,46)$. Furthermore, the lack of HSPG expression on the mouse pro-B cell surface severely impairs IL-7-dependent maturation toward pre-B cells suggesting that in this situation HS acts as a primary IL-7 receptor. In addition, HSPG can contribute to IL-7 biological activity by presenting IL-7 on stromal cells to promote lymphopoiesis in the bone marrow (47). In the thymus, however, the ability of stromal cell HSPGs to bind IL-7 and aid thymocytes development is dispensable (48). Depending on the degree of sulfation, cell surface HSPG has also been shown to potentiate the IFN- $\gamma$-IFN- $\gamma$-receptor interaction (49). Importantly, HSPG also facilitate cytokine localization in specific niches, forming depots where they can be made available to target cells. For instance, perlecan binds IL-2, sequestering it from the circulation and subsequently depositing the cytokine in the marginal zone and red pulp of the murine spleen to modulate murine T cells homeostasis (50). HSPGs also facilitate the storing of IL-2 within the vascular smooth muscle wall where cytokine availability is regulated through heparanase-mediated ECM degradation (51).

The ability to bind and present a chemokine to target cells is insufficient to drive cell migration, the hallmark of chemokine function. HSPGs are not only capable of binding and assisting in inducing conformational changes in bound chemokines $(52,53)$, but also contribute to the establishment of immobilized (haptotactic) chemokine gradients in tissues (54). For example, HSPG facilitate the oligomerization of bound RANTES/CCL5, CXCL8, MCP1 , and MIP-1, thereby allowing better recognition by their cognate G-protein-linked transmembrane receptors (55). In addition to the sequestration of CXCL2 (56), HSPG also mediate transcytosis of CXCL8 across the endothelium, presenting both chemokines on the luminal side and establishing haptotactic gradients that aid neutrophils recruitment during inflammation (36). In a separate study, the migration of tissue dendritic cells (DC) to regional lymph nodes and the local positioning of DC within lymph nodes was also found to be mediated by a HS-dependent haptotactic gradient of CCL21 (57). A similar interaction is believed to facilitate lymphocytes homing through the high endothelial venules into peripheral lymphoid organs $(58,59)$, although it is unclear if HS also influences local positioning in specific niches. Also, shedding of HSPG, such as syndecan-1 (60) and removal of glucosamine 6-O-sulfate by the endosulfatase, Sulf2 (6) has been implicated in regulating the interaction between HS and various chemokines. Furthermore, the inactivation of HS-modifying enzymes can modify neutrophil binding to the endothelium, Ndst1 (HS $N$-deacetylase/ $N$-sulfotransferase) deletion severely impairing (36), while Hs2st (HS 2-O-sulfotransferase) deletion significantly augmenting (61), neutrophil binding. These studies support the concept of regulating HS function by altering the availability of enzymes that are involved in HS biosynthesis.

\section{A SENSOR OF TISSUE INJURY}

Tissue injury may induce cell necrosis, an event that is often associated with the release of various endogenous damage-associated molecular pattern (DAMP)-containing molecules that are potent inducers of inflammatory responses and initiators of tissue repair mechanisms (62). Both surface bound HSPG and soluble HS participate in sensing tissue injury and also in repair mechanisms. For example, endothelial cell surface HS mediates the oligomerization of the receptor for advanced glycation endproducts (RAGE) (63) and together form a receptor complex that efficiently recognizes the chromatin protein, high-mobility group protein B1 (HMGB1) released from necrotic cells (64). As part of the tissue repair mechanism, HS on the surface of professional phagocytes also assists in the clearance of necrotic cells (65). In fact, soluble HS itself can also function as a DAMP (66) by interacting with TLR-4 on leukocytes (20). This interaction has been shown to modulate the release of pro-inflammatory cytokines by macrophages (67) and markedly induce the maturation of $\mathrm{DC}$, as indicated by the up-regulation of MHC-II, CD40, ICAM-1, CD80, CD86, and reduced antigen uptake, a typical phenotype of a professional antigen presenting cells (68). Although this is beneficial in triggering immune activation following an insult (20), it is also implicated in the underlying mechanism of disease progression which can occur in experimental pancreatitis (69), sepsis-like syndrome (70), hyperacute rejection in graft-versus-host disease (GvHD) (71), and cardiac injury (72).

\section{PHYSICAL BARRIER TO LEUKOCYTE MIGRATION}

The ECM/BM associated HS is crucial to form a temporary depot of HS-binding soluble factors and to form a physical barrier that supports tissue integrity. In order to migrate, particularly through blood vessel walls, leukocytes need to break down the ECM/BM barrier and heparanase is primarily involved in this process (10, 73). For example, tissue DCs increase the availability of cell surface heparanase to aid ECM degradation before migrating into lymphatic vessels leading toward regional lymph nodes where they 
induce antigen-specific responses (74). Subsequent studies have suggested that the matrix metalloproteinase, MMP-14, cooperatively works with heparanase to more efficiently degrade ECM/BM barriers (75). During inflammation, infiltrating monocytes and neutrophils also exhibit similar modes of degrading ECM/BM barriers to aid their extravasation $(76,77)$. It has also been demonstrated that heparanase derived from infiltrating leukocytes is primarily responsible for the destruction of the pancreatic islet $\beta$ cells that produce insulin, thereby providing a novel explanation for the underlying immunopathology of autoimmune Type 1 diabetes (78). In a separate study, leukocytes were shown to also use endogenous myeloperoxidase to produce oxidants that degrade the core protein of perlecan, releasing soluble factors and allowing leukocyte migration across ECM/BM barriers (79). Although HS can also be degraded by nitric oxide $(80,81)$ and reactive oxygen species (82-84), their direct relevance in the degradation of ECM/BM-associated HSPGs and therefore their contribution to leukocytes extravasation is yet to be elucidated.

\section{CONCLUDING REMARKS}

The evidence presented in this mini-review further corroborates the fundamental importance of HS in the mammalian immune system. HSPGs, primarily through their HS side chains, regulate various aspects of the immune system ranging from hematopoiesis to homing of leukocytes to peripheral tissues and, most importantly, regulating the elicitation of immune responses. Perturbing HS function or availability has been proven to results in various abnormal immune phenotypes. Furthermore, based on a simple bioinformatics screen presented in this review, it is suggested that HS may in fact interact with many more components of the immune system than previously realized. A better understanding of HS function across various systems is fundamental to exploit its potential in boosting beneficial immune responses and also in finding treatments for related immunopathologies.

\section{ACKNOWLEDGMENTS}

We acknowledge Mr. Cameron Jack from the Genome Discovery Unit (JCSMR) for his assistance in the bioinformatics screen for hypothetical HS-binding proteins.

\section{REFERENCES}

1. Kreuger J, Kjellen L. Heparan sulfate biosynthesis: regulation and variability. J Histochem Cytochem (2012) 60(12):898-907. doi:10.1369/0022155412464972

2. Esko JD, Selleck SB. Order out of chaos: assembly of ligand binding sites in heparan sulfate. Annu Rev Biochem (2002) 71:435-71. doi:10.1146/annurev. biochem.71.110601.135458

3. Peterson SB, Liu J. Unraveling the specificity of heparanase utilizing synthetic substrates. J Biol Chem (2010) 285(19):14504-13. doi:10.1074/jbc.M110.104166

4. Nagamine S, Tamba M, Ishimine H, Araki K, Shiomi K, Okada T, et al. Organ-specific sulfation patterns of heparan sulfate generated by extracellular sulfatases Sulf1 and Sulf2 in mice. J Biol Chem (2012) 287(12):9579-90. doi:10.1074/jbc.M111.290262

5. Hossain MM, Hosono-Fukao T, Tang R, Sugaya N, van Kuppevelt TH, Jenniskens GJ, et al. Direct detection of HSulf-1 and HSulf-2 activities on extracellular heparan sulfate and their inhibition by PI-88. Glycobiology (2010) 20(2):175-86. doi:10.1093/glycob/cwp159

6. Uchimura K, Morimoto-Tomita M, Bistrup A, Li J, Lyon M, Gallagher J, et al. HSulf-2, an extracellular endoglucosamine-6-sulfatase, selectively mobilizes heparin-bound growth factors and chemokines: effects on VEGF, FGF-1, and SDF-1. BMC Biochem (2006) 7:2. doi:10.1186/1471-2091-7-2
7. Kramer KL, Yost HJ. Heparan sulfate core proteins in cell-cell signaling. Annu Rev Genet (2003) 37:461-84. doi:10.1146/annurev.genet.37.061103.090226

8. Sarrazin S, Lamanna WC, Esko JD. Heparan sulfate proteoglycans. Cold Spring Harb Perspect Biol (2011) 3(7):1-33. doi:10.1101/cshperspect.a004952

9. Bernfield M, Gotte M, Park PW, Reizes O, Fitzgerald ML, Lincecum J, et al. Functions of cell surface heparan sulfate proteoglycans. Annu Rev Biochem (1999) 68:729-77. doi:10.1146/annurev.biochem.68.1.729

10. Parish CR. The role of heparan sulphate in inflammation. Nat Rev Immunol (2006) 6(9):633-43. doi:10.1038/nri1918

11. Kolset SO, Pejler G. Serglycin: a structural and functional chameleon with wide impact on immune cells. J Immunol (2011) 187(10):4927-33. doi:10.4049/ jimmunol.1100806

12. Richardson TP, Trinkaus-Randall V, Nugent MA. Regulation of heparan sulfate proteoglycan nuclear localization by fibronectin. J Cell Sci (2001) 114(Pt 9):1613-23.

13. Fedarko NS, Conrad HE. A unique heparan sulfate in the nuclei of hepatocytes: structural changes with the growth state of the cells. J Cell Biol (1986) 102(2):587-99. doi:10.1083/jcb.102.2.587

14. Buczek-Thomas JA, Hsia E, Rich CB, Foster JA, Nugent MA. Inhibition of histone acetyltransferase by glycosaminoglycans. J Cell Biochem (2008) 105(1):108-20. doi:10.1002/jcb.21803

15. Purushothaman A, Hurst DR, Pisano C, Mizumoto S, Sugahara K, Sanderson RD. Heparanase-mediated loss of nuclear syndecan-1 enhances histone acetyltransferase (HAT) activity to promote expression of genes that drive an aggressive tumor phenotype. J Biol Chem (2011) 286(35):30377-83. doi:10.1074/jbc. M111.254789

16. Chen L, Sanderson RD. Heparanase regulates levels of syndecan-1 in the nucleus. PLoS One (2009) 4(3):e4947. doi:10.1371/journal.pone.0004947

17. Hileman RE, Fromm JR, Weiler JM, Linhardt RJ. Glycosaminoglycan-protein interactions: definition of consensus sites in glycosaminoglycan binding proteins. Bioessays (1998) 20(2):156-67. doi:10.1002/(SICI)1521-1878(199802)20: $2<156:: A I D-B I E S 8>3.3 . C O ; 2-\backslash \#$

18. Cardin AD, Weintraub HJ. Molecular modeling of protein-glycosaminoglycan interactions. Arteriosclerosis (1989) 9(1):21-32. doi:10.1161/01.ATV.9.1.21

19. Lu CP, Sandoval H, Brandt VL, Rice PA, Roth DB. Amino acid residues in Rag1 crucial for DNA hairpin formation. Nat Struct Mol Biol (2006) 13(11):1010-5. doi:10.1038/nsmb1154

20. Johnson GB, Brunn GJ, Kodaira Y, Platt JL. Receptor-mediated monitoring of tissue well-being via detection of soluble heparan sulfate by Toll-like receptor 4 . J Immunol (2002) 168(10):5233-9.

21. Wuillemin WA, te Velthuis H, Lubbers YT, de Ruig CP, Eldering E, Hack CE. Potentiation of $\mathrm{C} 1$ inhibitor by glycosaminoglycans: dextran sulfate species are effective inhibitors of in vitro complement activation in plasma. J Immunol (1997) 159(4):1953-60.

22. Sahu A, Pangburn MK. Identification of multiple sites of interaction between heparin and the complement system. Mol Immunol (1993) 30(7):679-84. doi:10.1016/0161-5890(93)90079-Q

23. Presanis JS, Hajela K, Ambrus G, Gal P, Sim RB. Differential substrate and inhibitor profiles for human MASP-1 and MASP-2. Mol Immunol (2004) 40(13):921-9. doi:10.1016/j.molimm.2003.10.013

24. Diamond MS, Alon R, Parkos CA, Quinn MT, Springer TA. Heparin is an adhesive ligand for the leukocyte integrin Mac-1 (CD11b/CD1). J Cell Biol (1995) 130(6):1473-82. doi:10.1083/jcb.130.6.1473

25. Vorup-Jensen T, Chi L, Gjelstrup LC, Jensen UB, Jewett CA, Xie C, et al. Binding between the integrin alphaXbeta2 (CD11c/CD18) and heparin. J Biol Chem (2007) 282(42):30869-77. doi:10.1074/jbc.M706114200

26. Zaferani A, Talsma D, Richter MK, Daha MR, Navis GJ, Seelen MA, et al. Heparin/heparan sulphate interactions with complement - a possible target for reduction of renal function loss? Nephrol Dial Transplant (2013) 1-9. doi:10.1093/ndt/gft243

27. Hacker U, Nybakken K, Perrimon N. Heparan sulphate proteoglycans: the sweet side of development. Nat Rev Mol Cell Biol (2005) 6(7):530-41. doi:10.1038/ nrm 1681

28. Bishop JR, Schuksz M, Esko JD. Heparan sulphate proteoglycans fine-tune mammalian physiology. Nature (2007) 446(7139):1030-7. doi:10.1038/ nature 05817

29. Lindahl U, Kjellen L. Pathophysiology of heparan sulphate: many diseases, few drugs. J Intern Med (2013) 273(6):555-71. doi:10.1111/joim.12061 
30. Coombe DR, Watt SM, Parish CR. Mac-1 (CD11b/CD18) and CD45 mediate the adhesion of hematopoietic progenitor cells to stromal cell elements via recognition of stromal heparan sulfate. Blood (1994) 84(3):739-52.

31. Khurana S, Margamuljana L, Joseph C, Schouteden S, Buckley SM, Verfaillie CM. Glypican-3-mediated inhibition of CD26 by TFPI: a novel mechanism in hematopoietic stem cell homing and maintenance. Blood (2013) 121(14):2587-95. doi:10.1182/blood-2012-09-456715

32. Werneck CC, Oliveira-Dos-Santos AJ, Silva LC, Villa-Verde DM, Savino W, Mourao PA. Thymic epithelial cells synthesize a heparan sulfate with a highly sulfated region. J Cell Physiol (1999) 178(1):51-62. doi:10.1002/(SICI)10974652(199901)178:1<51::AID-JCP7>3.3.CO;2-K

33. Werneck CC, Cruz MS, Silva LC, Villa-Verde DM, Savino W, Mourao PA. Is there a glycosaminoglycan-related heterogeneity of the thymic epithelium? J Cell Physiol (2000) 185(1):68-79. doi:10.1002/1097-4652(200010)185:1<68::AIDJCP6>3.0.CO;2-D

34. Oliveira-dos-Santos AJ, Penninger JM, Rieker-Geley T, Matsumoto G, Mak TM, Wick G. Thymic heterotypic cellular complexes in gene-targeted mice with defined blocks in $\mathrm{T}$ cell development and adhesion molecule expression. Eur J Immunol (1998) 28(9):2882-92. doi:10.1002/(SICI)1521-4141(199809) 28:09<2882::AID-IMMU2882>3.0.CO;2-1

35. Oliveira-dos-Santos AJ, Rieker-Geley T, Recheis H, Wick G. Murine thymic nurse cells and rosettes: analysis of adhesion molecule expression using confocal microscopy and a simplified enrichment method. J Histochem Cytochem (1997) 45(9):1293-7. doi:10.1177/002215549704500912

36. Wang L, Fuster M, Sriramarao P, Esko JD. Endothelial heparan sulfate deficiency impairs L-selectin- and chemokine-mediated neutrophil trafficking during inflammatory responses. Nat Immunol (2005) 6(9):902-10. doi:10.1038/ni1233

37. Zen K, Liu DQ, Li LM, Chen CX, Guo YL, Ha B, et al. The heparan sulfate proteoglycan form of epithelial CD44v3 serves as a CD11b/CD18 counter-receptor during polymorphonuclear leukocyte transepithelial migration. J Biol Chem (2009) 284(6):3768-76. doi:10.1074/jbc.M807805200

38. Kawashima H, Watanabe N, Hirose M, Sun X, Atarashi K, Kimura T, et al. Collagen XVIII, a basement membrane heparan sulfate proteoglycan, interacts with L-selectin and monocyte chemoattractant protein-1. J Biol Chem (2003) 278(15):13069-76. doi:10.1074/jbc.M212244200

39. Celie JW, Keuning ED, Beelen RH, Drager AM, Zweegman S, Kessler FL, et al. Identification of L-selectin binding heparan sulfates attached to collagen type XVIII. J Biol Chem (2005) 280(29):26965-73. doi:10.1074/jbc.M502188200

40. Schmidt EP, Yang Y, Janssen WJ, Gandjeva A, Perez MJ, Barthel L, et al. The pulmonary endothelial glycocalyx regulates neutrophil adhesion and lung injury during experimental sepsis. Nat Med (2012) 18(8):1217-23. doi:10.1038/nm. 2843

41. Giuffre L, Cordey AS, Monai N, Tardy Y, Schapira M, Spertini O. Monocyte adhesion to activated aortic endothelium: role of L-selectin and heparan sulfate proteoglycans. J Cell Biol (1997) 136(4):945-56. doi:10.1083/jcb.136.4.945

42. Kharabi Masouleh B, Ten Dam GB, Wild MK, Seelige R, van der Vlag J, Rops $\mathrm{AL}$, et al. Role of the heparan sulfate proteoglycan syndecan-1 (CD138) in delayed-type hypersensitivity. J Immunol (2009) 182(8):4985-93. doi:10.4049/ jimmunol.0800574

43. Handel TM, Johnson Z, Crown SE, Lau EK, Proudfoot AE. Regulation of protein function by glycosaminoglycans - as exemplified by chemokines. Annu Rev Biochem (2005) 74:385-410. doi:10.1146/annurev.biochem.72.121801.161747

44. Coombe DR. Biological implications of glycosaminoglycan interactions with haemopoietic cytokines. Immunol Cell Biol (2008) 86(7):598-607. doi:10.1038/ icb. 2008.49

45. Clarke D, Katoh O, Gibbs RV, Griffiths SD, Gordon MY. Interaction of interleukin 7 (IL-7) with glycosaminoglycans and its biological relevance. Cytokine (1995) 7(4):325-30. doi:10.1006/cyto.1995.0041

46. Lortat-Jacob H, Grimaud JA. Interferon-gamma C-terminal function: new working hypothesis. Heparan sulfate and heparin, new targets for IFN-gamma, protect, relax the cytokine and regulate its activity. Cell Mol Biol (1991) 37(3):253-60.

47. Borghesi LA, Yamashita Y, Kincade PW. Heparan sulfate proteoglycans mediate interleukin-7-dependent B lymphopoiesis. Blood (1999) 93(1):140-8.

48. Banwell CM, Partington KM, Jenkinson EJ, Anderson G. Studies on the role of IL-7 presentation by mesenchymal fibroblasts during early thymocyte development. Eur J Immunol (2000) 30(8):2125-9. doi:10.1002/1521-4141(2000)30: $8<2125:: A I D-$ IMMU2125>3.0.CO;2-H
49. Sadir R, Forest E, Lortat-Jacob H. The heparan sulfate binding sequence of interferon-gamma increased the on rate of the interferon-gamma-interferongamma receptor complex formation. J Biol Chem (1998) 273(18):10919-25. doi:10.1074/jbc.273.18.10919

50. Miller JD, Stevens ET, Smith DR, Wight TN, Wrenshall LE. Perlecan: a major IL2-binding proteoglycan in murine spleen. Immunol Cell Biol (2008) 86(2):192-9. doi:10.1038/sj.icb.7100128

51. Miller JD, Clabaugh SE, Smith DR, Stevens RB, Wrenshall LE. Interleukin-2 is present in human blood vessels and released in biologically active form by heparanase. Immunol Cell Biol (2012) 90(2):159-67. doi:10.1038/icb.2011.45

52. Proudfoot AE, Handel TM, Johnson Z, Lau EK, LiWang P, Clark-Lewis I, et al. Glycosaminoglycan binding and oligomerization are essential for the in vivo activity of certain chemokines. Proc Natl Acad Sci US A (2003) 100(4):1885-90. doi:10.1073/pnas.0334864100

53. Salanga CL, Handel TM. Chemokine oligomerization and interactions with receptors and glycosaminoglycans: the role of structural dynamics in function. Exp Cell Res (2011) 317(5):590-601. doi:10.1016/j.yexcr.2011.01.004

54. Laguri C, Arenzana-Seisdedos F, Lortat-Jacob H. Relationships between glycosaminoglycan and receptor binding sites in chemokines-the CXCL12 example. Carbohydr Res (2008) 343(12):2018-23. doi:10.1016/j.carres.2008.01.047

55. Hoogewerf AJ, Kuschert GS, Proudfoot AE, Borlat F, Clark-Lewis I, Power CA, et al. Glycosaminoglycans mediate cell surface oligomerization of chemokines. Biochemistry (1997) 36(44):13570-8. doi:10.1021/bi971125s

56. Massena S, Christoffersson G, Hjertstrom E, Zcharia E, Vlodavsky I, Ausmees N, et al. A chemotactic gradient sequestered on endothelial heparan sulfate induces directional intraluminal crawling of neutrophils. Blood (2010) 116(11):1924-31. doi:10.1182/blood-2010-01-266072

57. Weber M, Hauschild R, Schwarz J, Moussion C, de Vries I, Legler DF, et al. Interstitial dendritic cell guidance by haptotactic chemokine gradients. Science (2013) 339(6117):328-32. doi:10.1126/science.1228456

58. Bao X, Moseman EA, Saito H, Petryniak B, Thiriot A, Hatakeyama S, et al. Endothelial heparan sulfate controls chemokine presentation in recruitment of lymphocytes and dendritic cells to lymph nodes. Immunity (2010) 33(5):817-29. doi:10.1016/j.immuni.2010.10.018

59. Tsuboi K, Hirakawa J, Seki E, Imai Y, Yamaguchi Y, Fukuda M, et al. Role of high endothelial venule-expressed heparan sulfate in chemokine presentation and lymphocyte homing. J Immunol (2013) 191(1):448-55. doi:10.4049/jimmunol. 1203061

60. Hayashida K, Parks WC, Park PW. Syndecan-1 shedding facilitates the resolution of neutrophilic inflammation by removing sequestered CXC chemokines. Blood (2009) 114(14):3033-43. doi:10.1182/blood-2009-02-204966

61. Axelsson J, Xu D, Kang BN, Nussbacher JK, Handel TM, Ley K, et al. Inactivation of heparan sulfate 2-O-sulfotransferase accentuates neutrophil infiltration during acute inflammation in mice. Blood (2012) 120(8):1742-51. doi:10.1182/blood-2012-03-417139

62. Kono H, Rock KL. How dying cells alert the immune system to danger. Nat Rev Immunol (2008) 8(4):279-89. doi:10.1038/nri2215

63. Xu D, Young JH, Krahn JM, Song D, Corbett KD, Chazin WJ, et al. Stable RAGEheparan sulfate complexes are essential for signal transduction. ACS Chem Biol (2013) 1611-20. doi:10.1021/cb4001553

64. Xu D, Young J, Song D, Esko JD. Heparan sulfate is essential for high mobility group protein 1 (HMGB1) signaling by the receptor for advanced glycation end products (RAGE). J Biol Chem (2011) 286(48):41736-44. doi:10.1074/jbc. M111.299685

65. Poon IK, Parish CR, Hulett MD. Histidine-rich glycoprotein functions cooperatively with cell surface heparan sulfate on phagocytes to promote necrotic cell uptake. J Leukoc Biol (2010) 88(3):559-69. doi:10.1189/jlb.0210087

66. Ihrcke NS, Wrenshall LE, Lindman BJ, Platt JL. Role of heparan sulfate in immune system-blood vessel interactions. Immunol Today (1993) 14(10):500-5. doi:10.1016/0167-5699(93)90265-M

67. Wrenshall LE, Stevens RB, Cerra FB, Platt JL. Modulation of macrophage and B cell function by glycosaminoglycans. J Leukoc Biol (1999) 66(3):391-400.

68. Kodaira Y, Nair SK, Wrenshall LE, Gilboa E, Platt JL. Phenotypic and functional maturation of dendritic cells mediated by heparan sulfate. J Immunol (2000) 165(3):1599-604.

69. Akbarshahi H, Axelsson JB, Said K, Malmstrom A, Fischer H, Andersson R. TLR4 dependent heparan sulphate-induced pancreatic inflammatory response is IRF3-mediated. J Transl Med (2011) 9:219. doi:10.1186/1479-5876-9-219 
70. Johnson GB, Brunn GJ, Platt JL. Cutting edge: an endogenous pathway to systemic inflammatory response syndrome (SIRS)-like reactions through Toll-like receptor 4. J Immunol (2004) 172(1):20-4.

71. Brennan TV, Lin L, Huang X, Cardona DM, Li Z, Dredge K, et al. Heparan sulfate, an endogenous TLR4 agonist, promotes acute GVHD after allogeneic stem cell transplantation. Blood (2012) 120(14):2899-908. doi:10.1182/blood-201107-368720

72. Strand ME, Herum KM, Rana ZA, Skrbic B, Askevold ET, Dahl CP, et al. Innate immune signaling induces expression and shedding of the heparan sulfate proteoglycan syndecan-4 in cardiac fibroblasts and myocytes, affecting inflammation in the pressure-overloaded heart. FEBS J (2013) 280(10):2228-47. doi: $10.1111 /$ febs. 12161

73. Vlodavsky I, Eldor A, Haimovitz-Friedman A, MatznerY, Ishai-Michaeli R, Lider $\mathrm{O}$, et al. Expression of heparanase by platelets and circulating cells of the immune system: possible involvement in diapedesis and extravasation. Invasion Metastasis (1992) 12(2):112-27.

74. Benhamron S, Nechushtan H, Verbovetski I, Krispin A, Abboud-Jarrous G, Zcharia E, et al. Translocation of active heparanase to cell surface regulates degradation of extracellular matrix heparan sulfate upon transmigration of mature monocyte-derived dendritic cells. J Immunol (2006) 176(11):6417-24.

75. Benhamron S, Reiner I, Zcharia E, Atallah M, Grau A, Vlodavsky I, et al. Dissociation between mature phenotype and impaired transmigration in dendritic cells from heparanase-deficient mice. PLoS One (2012) 7(5):e35602. doi:10.1371/journal.pone.0035602

76. Matzner Y, Bar-Ner M, Yahalom J, Ishai-Michaeli R, Fuks Z, Vlodavsky I. Degradation of heparan sulfate in the subendothelial extracellular matrix by a readily released heparanase from human neutrophils. Possible role in invasion through basement membranes. J Clin Invest (1985) 76(4):1306-13. doi:10.1172/JCI112104

77. Sasaki N, Higashi N, Taka T, Nakajima M, Irimura T. Cell surface localization of heparanase on macrophages regulates degradation of extracellular matrix heparan sulfate. J Immunol (2004) 172(6):3830-5.

78. Ziolkowski AF, Popp SK, Freeman C, Parish CR, Simeonovic CJ. Heparan sulfate and heparanase play key roles in mouse beta cell survival and autoimmune diabetes. J Clin Invest (2012) 122(1):132-41. doi:10.1172/JCI46177

79. Rees MD, Whitelock JM, Malle E, Chuang CY, Iozzo RV, Nilasaroya A, et al. Myeloperoxidase-derived oxidants selectively disrupt the protein core of the heparan sulfate proteoglycan perlecan. Matrix Biol (2010) 29(1):63-73. doi:10. 1016/j.matbio.2009.09.005
80. Vilar RE, Ghael D, Li M, Bhagat DD, Arrigo LM, Cowman MK, et al. Nitric oxide degradation of heparin and heparan sulphate. Biochem J (1997) 324(Pt 2):473-9.

81. Mani K, Jonsson M, Edgren G, Belting M, Fransson LA. A novel role for nitric oxide in the endogenous degradation of heparan sulfate during recycling of glypican-1 in vascular endothelial cells. Glycobiology (2000) 10(6):577-86. doi:10.1093/glycob/10.6.577

82. Rao G, Ding HG, Huang W, Le D, Maxhimer JB, Oosterhof A, et al. Reactive oxygen species mediate high glucose-induced heparanase-1 production and heparan sulphate proteoglycan degradation in human and rat endothelial cells: a potential role in the pathogenesis of atherosclerosis. Diabetologia (2011) 54(6):1527-38. doi:10.1007/s00125-011-2110-z

83. Singh A, Ramnath RD, Foster RR, Wylie EC, Friden V, Dasgupta I, et al. Reactive oxygen species modulate the barrier function of the human glomerular endothelial glycocalyx. PLoS One (2013) 8(2):e55852. doi:10.1371/journal.pone. 0055852

84. Raats CJ, Bakker MA, van den Born J, Berden JH. Hydroxyl radicals depolymerize glomerular heparan sulfate in vitro and in experimental nephrotic syndrome. J Biol Chem (1997) 272(42):26734-41. doi:10.1074/jbc.272.42.26734

Conflict of Interest Statement: The authors declare that the research was conducted in the absence of any commercial or financial relationships that could be construed as a potential conflict of interest.

Received: 14 October 2013; accepted: 05 December 2013; published online: 18 December 2013.

Citation: Simon Davis DA and Parish CR (2013) Heparan sulfate: a ubiquitous glycosaminoglycan with multiple roles in immunity. Front. Immunol. 4:470. doi: 10.3389/fimmu.2013.00470

This article was submitted to Inflammation, a section of the journal Frontiers in Immunology.

Copyright (C) 2013 Simon Davis and Parish. This is an open-access article distributed under the terms of the Creative Commons Attribution License (CC BY). The use, distribution or reproduction in other forums is permitted, provided the original author(s) or licensor are credited and that the original publication in this journal is cited, in accordance with accepted academic practice. No use, distribution or reproduction is permitted which does not comply with these terms. 